\title{
Pelatihan Peningkatan Kemampuan Berkomunikasi Menggunakan Bahasa Inggris dalam Memberikan Pelayanan Prima pada Industri Perhotelan di Balikpapan
}

\author{
Elisabeth Milaningrum ${ }^{1 *}$; Patria Rahmawati ${ }^{2}$; Zulkifli² ${ }^{2}$ Subur Mulyanto ${ }^{2}$ \\ ${ }^{1}$ Jurusan Perhotelan Politeknik Negeri Balikpapan \\ ${ }^{2}$ Jurusan Teknik Mesin Politeknik Negeri Balikpapan \\ ${ }^{*}$ elisabeth.milaningrum@poltekba.ac.id
}

\begin{abstract}
Abstrak
Pesatnya pertumbuhan hotel di Balikpapan ini sangat perlu diimbangi dengan peningkatan kapasitas pekerja pada industri perhotelan seiring dengan terjadinya penambahan jumlah tamu mancanegara yang datang sehingga diperlukan pelayanan prima guna terwujudnya kepuasaan pelanggan. Komunikasi merupakan salah satu faktor terpenting ketika memberikan pelayanan prima kepada tamu hotel khususnya tamu mancanegara yang menuntut semua karyawan hotel dapat fasih berkomunikasi dengan menggunakan bahasa Inggris. Permasalahan yang dijumpai pada mitra PKM yakni rendahnya kemampuan berkomunikasi menggunakan bahasa Inggris pada pekerja perhotelan sehingga tidak dapat memberikan pelayanan prima. Metode pemecahan masalah dilakukan melalui 4 tahapan yakni persiapan, perumusan masalah, pelaksanaan yang meliputi pelatihan Bahasa Inggris serta pendampingan, dan evaluasi program. Berdasarkan hasil PKM yang telah diikuti oleh 40 karyawan perhotelan, maka dapat disimpulkan bahwa terjadi peningkatan kemampuan berkomunikasi menggunakan bahasa Inggris secara signifikan dan berdasarkan hasil dari kegiatan pendampingan serta evaluasi, dapat dinyatakan bahwa karyawan hotel yang mengikuti pelatihan sangat terbantu dengan adanya pelatihan ini dan dapat meningkatkan rasa percaya diri pekerja hotel ketika berkomunikasi dengan tamu hotel mancanegara.
\end{abstract}

Kata Kunci: bahasa Inggris, industri perhotelan, komunikasi, pelatihan, pelayanan prima

\section{Abstract}

The fast growth of hotel in Balikpapan must be balanced with the improvement of hotel employees' competence in hospitality industry along with the increasing of foreign countries guest that is needed excellent service in order to fulfill the guests satisfaction. Communication is one of the most importantant aspect while giving excellent service to the guests especially to foreign countries guest that demand all of the hotel employees can communicate in English fluently. The problems that was found for our community service partner was the low English communication competence of hospitality employee therefore they cannot give excellent service. Method that was used to solve the problem was done through 4 steps, such as: preparation, problem formulation, implementation that consists of English training and mentoring, and evaluation program. Based on the result of our community service that has followed by 40 hospitality employees, it can be concluded that there is significant progress of English communication competence for each hospitality employee which has followed English training and also based on the result of mentoring and evaluation, it is stated that this community service programe through English training for giving excellent service can help hospitality employees to increase their self confidence while communicate with foreign countries guest.

Keywords: English, hospitality industry, communication, training, excellent service

\section{Pendahuluan}

Balikpapan merupakan salah satu daerah di provinsi Kalimanatan Timur yang memiliki fasilitas akomodasi yang cukup beragam. Berbagai hotel dan penginapan tersedia di Balikpapan dari hotel melati, hotel bintang satu sampai hotel bintang lima. Hotel merupakan salah satu penunjang sebuah daerah dapat dikunjungi banyak orang dan menjadi salah satu daya tarik destinasi wisata. Pada tahun 2014, data BPS menyebutkan bahwa jumlah hotel yang terdapat di Balikpapan hanya 59 hotel. Seiring peningkatan ekonomi dan kebutuhan, jumlah hotel mengalami peningkatan yang cukup signifikan pada tahun 2015 menjadi 67 hotel dan pada tahun 2016 juga mengalami peningkatan jumlah hotel menjadi 80 hotel. Menurut PHRI (Perhimpunan Hotel dan Restoran Indonesia) akan terjadi peningkatan yang lebih signifikan ditahun berikutnya dengan ditetapkannya ibu kota di 
Kalimantan Timur yang akan memberikan imbas besar pada industri perhotelan di Balikpapan sebagia kota penopang calon ibu kota. Peningkatan jumlah hotel di Balikpapan merupakan peningkatan paling tinggi diantara kabupaten/kota yang terdapat di Kalimantan Timur. Seiring dengan peningkatan jumlah hotel dari tahun ke tahun, maka perlu diimbangi juga dengan peningkatan kualitas pelayanan hotel dengan memberikan pelayanan prima terhadap setiap tamu hotel yang datang.

Hotel merupakan salah satu industri pariwisata yang dalam praktiknya sangat memperhatikan sikap pelayanan prima (excellent service) kepada setiap tamu hotel yang datang. Menurut Rumekso (2002), kata service ini pun memiliki makna tersendir dalam dunia perhotelan yakni $\mathrm{S}=$ Smile to everyone (berikan senyuman kepada semua orang), $\mathrm{E}=$ Excellent in everything we do (kerjakan semuanya semaksimal mungkin dan memuaskan), $\mathrm{R}=$ Reaching out to every guest with hospitality (jangkau dan dekati tamu dengan penuh ramah- tamah), $\mathrm{V}=$ Viewing every guest as special (memandang dengan rasa yang sangat penuh perhatian), I = Inviting guest to return (melakukan segala sesuatu terhadap tamu yang akan membuat tamu tersebut datang kembali), $\mathrm{C}=$ Creating a warm atmosphere ( selalu menciptakan suasana yang akrab/hangat terhadap tamu, $\mathrm{E}=$ Eye contact that shows we care (mata sesekali harus kontak dengan pandangan tamu).

Menurut Suryadharma \& Nurcahya (2015), reputasi sebuah hotel sangat ditentukan dari sikap, perilaku, pelayanan, dan kualitas yang diberikan kepada para tamu dan wisatawan. Hal ini merupakan tugas utama dari manajemen dan karyawan hotel, untuk memberikan pelayanan prima. Tidak hanya menjadi tugas frontliner (staf garis depan) yang wajib memberikan pelayanan prima tetapi juga menjadi tugas karyawan back office, untuk menjadi pendukung yang tangguh, sehingga frontliner dapat memberikan yang terbaik dan berkualitas kepada para tamu hotel. Susepti, dkk.(2017) menyatakan bahwa pelayanan prima yang diberikan oleh karyawan hotel dapat menciptakan pengalaman yang tak terlupakan dan membuat tamu ingin menginap kembali sehingga tamu hotel tersebut dapat menjadi marketing yang akan memberitahu kolega serta kerabatnya untuk menginap di hotel yang dirasakan pelayanannya luar biasa menyenangkan. Oleh karena itu, semua pelayanan di hotel dituntut memiliki kualitas yang baik dan mampu memuaskan konsumen yang datang, terlebih lagi jika konsumen yang dilayaninya adalah wisatawan mancanegara yang menuntut standar pelayanan tinggi yakni standar internasional dimana menuntut setiap karyawan hotel dapat berkomunikasi menggunakan bahasa Inggris dengan fasih dan komunikatif dengan tepat. Oleh karena itu dapat disimpulan bahwa komunikasi merupakan aspek terpenting dalam memberikan pelayanan prima dan diperlukan peningkatan kualitas SDM perhotelan seiring dengan permintaan pasar.

Berdasarkan hasil wawancara dengan GM Hotel Pasific Balikpapan yang merupakan mitra PKM kami menyatakan bahwa salah satu kelemahan dari kebanyak staff perhotelan yakni kurangnya kemampuan berkomunikasi menggunakan bahasa Inggris sehingga kurang dapat memberikan pelayan prima kepada tamu hotel, terlebih di Balikpapan ini merupakan kota minyak yang banyak akan tamu mancanegara yang singgah baik untuk keperluan bisnis maupun berlibur menikmati wisata di kota Balikpapan. Dengan memahami permasalahan tersebut, maka melalui program pelatihan peningkatan kemampuan komunikasi menggunakan Bahasa Inggris dalam memberikan pelayanan prima pada industri perhotelan di Balikpapan ini dapat meningkatkan kefasihan karyawan perhotelan dalam berkomunikasi dengan tamu khususnya tamu mancanegara serta dapat memberikan motivasi dan pencerahan dibidang pelayanan dan kinerja bagi karyawan hotel sehingga setiap karyawan hotel dapat lebih percaya diri dalam berkomunikasi menggunakan bahasa Inggris serta memotivasi karyawan hotel lebih meningkatkan kerja sama di dalam pelayanan. Dalam pelatihan ini akan dibahas mengenai beberapa topik yang digunakan dalam industri perhotelan dalam berkomunikasi sehingga output akhir dari hasil pelatihan ini dapat terjadi peningkatan kemampuan Bahasa Inggris staff perhotelan dalam berkomunikasi menggunakan Bahasa Inggris serta dapat meningkakan rasa percaya diri dan motivasi untuk terus belajar dan berlatih tentang ESP ( English for Specific Purposes) for hospitality.

\section{Bahan dan Metode}

Kegiatan pengabdian kepada masyarakat ini dilakukan melalui 4 tahapan yakni persiapan, perumusan masalah, pelaksanaan yang meliputi pelatihan serta pendampingan, dan evaluasi program. Alur kegiatan pengabdian diilustrasikan sebagai berikut.

Tahap awal dari kegiatan ini adalah tahap persiapan dimana tim PKM melakukan survei ke lokasi mitra, kemudian melakukan pengamatan untuk melihat situasi dan kondisi mitra serta mengidentifikasi permasalahan yang dihadapi mitra. Semua data dan informasi yang diperoleh dari lokasi 
mitra kemudian dianalisa sebagai dasar untuk merumuskan strategi atau langkah-langah kongkrit untuk menentukan prioritas masalah dan cara mengatasi masalah yang dihadapi mitra.

Dari hasil kajian informasi dan data serta diskusi dengan mitra pada tahap persiapan, maka dapat dirumuskan bahwa permasalahan yang sedang dihadapi mitra yakni terdapat kesulitan bagi staff perhotelan dalam berkomunikasi menggunakan bahasa inggis sehingga kurang dapat memberikan pelayanan prima khususnya bagi tamu mancanegara.

Untuk membantu mitra menyelesaikan permasalahan yang dihadapi tersebut, maka tim pelaksana pengabdian merancang pelatihan peningkanan komunikasi menggunakan bahasa Inggris dalam memberikan pelayanan prima melalui beberapa tahapan. Tahap pertama adalah menentukan tujuan pelatihan yakni untuk meningkatan kemampuan Bahasa Inggris staff perhotelan dalam berkomunikasi menggunakan Bahasa Inggris guna menunjang tercapianya pelayanan prima dengan menggunakan ESP for hospitality. Tahap kedua adalah menentukan keterampilan bahasa (language skills) yang paling paling utama yakni berbicara (speaking) dimana terintegarasi dengan kemampuan mendengarkan (listening), membaca (reading), dan menulis (writing). Hal terpenting adalah bagaimana mengubah mindset staff perhotelan untuk tidak hanya fokus pada sistem bahasa yang meliputi : vocabulary, structure, pronounciation, dan register, melainkan lebih mengajarkan untuk mempelajari skill kemampuan bahasa Inggris maka secara otomatis system bahasa Inggris itupun akan berkembang dengan sendirinya. Langkah ketiga adalah menentukan metode pembelajaran yang sesuai untuk menciptakan suasa kelas yang interaktif dan komunikatif dengan menggunakan berbagai metode pembelaran yang menitikberatkan pada peserta pelatihan. Menurut Susanti \& Rukiati (2017) terdapat beberapa metode pembelajaran yang interaktif pada saat pelaksanakan pelatihan diantaranya coopertaive learning, bermain peran (role play), diskusi dalam kelompok kecil (small- group discussion), bekerja secara berpasangan (pair-work), dan presentasi (presentation).

Pada tahap ketiga dilakukan pelaksanaan yang meliputi pelatihan serta pendampingan. Pelatihan dilakukan selama tiga hari yakni 29 Juli-31 Juli 2019 di Hotel Pasific Balikpapan yang diikuti oleh 40 peserta staff perhotelan yang terdiri dari 10 staff divisi front office, 4 staff divisi food and beverage, 4 staff divisi accounting, 10 staff divisi housekeeper, 2 staff divisi human resources, 3 staff divisi engineering, 3 staff divisi sales, 2 staff security dan 2 driver. Selain itu, dalam pelatihan ini juga melibatkan 2 mahasiswi prodi dividi kamar jurusan perhotelan Politeknik Negeri Balikpapan dan satu tenaga kependidikan. Setelah pelaksanaan kegiatan selesai, kemudian diikuti dengan dengan kegiatan pendampingan kepada setiap peserta pelatihan. Kemudian pada tahap terakhir yakni evalasi dimana tim PKM melakukan uji evaluasi hasil pelatihan dengan melakukan kunjungan ke setiap divisi peserta pelatihan untuk mengetahui seberapa besar keberhasilan pelatihan ini serta progress peningkatan kemampuan bahasa inggris staff perhotelan tersebut.

\section{Hasil dan Pembahasan}

Sasaran dalam kegiatan pelatihan ini yakni memberikan pembekalan mengenai pelayanan prima sebagai pekerja industi perhotelan dan juga peningkatan kemampuan bahasa Inggris dengan output pelatihan yang diharapkan yakni setiap peserta dapat:

1. Melakukan percakapan berbahasa Inggris secara tepat, lancar, dan natural

2. Menerima pengarahan lisan dan tertulis dalam bahasa Inggris

3. Memberikan petunjuk tentang lokasi dalam bahasa Inggris

4. Berkomunikasi tentang pelayanan hotel dengan tamu dalam Bahasa Inggris

5. Berkomunikasi dalam bahasa Inggris melalui telepon.

Dalam pertemuan pertama yang diikuti oleh 40 staff perhotelan diberikan materi mengenai pengantar pelayanan prima pada industri perhotelan khususnya menghadapi tamu mancanegara serta pemberian background knowledge mengenai cross culture understanding ketika menghadapi tamu yang berasal dari berbagai negara yang dibawakan oleh psikolog yang merupakan salah satu anggota tim PKM kami. Selain itu, juga diberikan pengenalan kosa kata pada ESP (English for Specific Purposes) for hospitality secara general, mempelajari excellent service in English serta aplikasi dalam pelayanan di industri perhotelan yang dibawakan oleh english trainer for hospitality yang merupakan ketua tim PKM kegitan ini. 


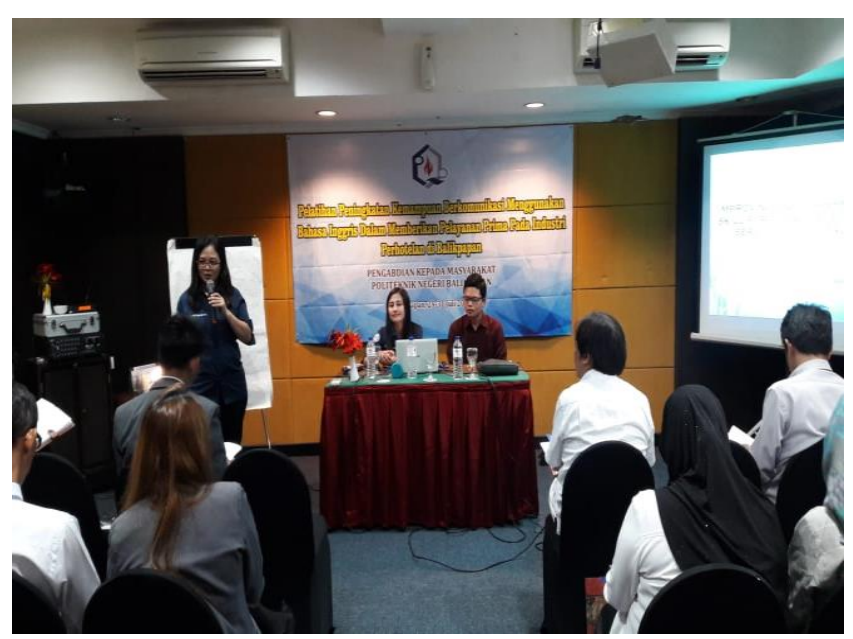

Gambar 1 Pengantar Pelayanan Prima pada Industri Perhotelan

Pada hari kedua, dimana peserta pelatihan sudah dibagi menjadi dua kelompok yakni kelompok staff pada divisi front liner dan back office. Materi pelatihan dibagi menjadi dua yakni materi umum perhotelan yang dilaksanakan pada pelatihan hari kedua dan materi inti yang dilaksanakan pada hari ketiga. Pada materi umum, English trainer memberikan 4 topik yang dibahas dalam pelatihan. Menurut Muliana (2017), materi umum yang diberikan pada staff perhotelan terdiri dari percakapan awal dengan tamu, menerima pengarahan lisan dan tertulis, memberikan petunjuk tentang lokasi, dan berkomunikasi melalui telepon. Ditengah-tengah kegiatan ini, juga diberikan ice breaking dan role play untuk mempraktekan setiap materi agar setiap peserta tidahk hanya mendapat materi tetapi juga practice. Dalam seminar ini, English trainer juga memberikan simulasi serta video percakapan dari native speaker mengenai percakapan pada industryi perhotelan, dan kemudian peserta diminta untuk drilling dan melakukan roleplay. Selain itu, trainer juga memotivasi peserta agar dapat lancar berbicara menggunakan bahasa Inggris secara natural tanpa harus menghapalkan formula tenses, atau apapun yang berhubungan dengan sistem bahasa sehingga peserta pelatihan dapat lebih berani mempraktekan komunikasi menggunakan bahasa Inggris dengan hanya memahami kontek waktu serta dapat membuat kalimat yang efektif dalam bahasa Inggris.

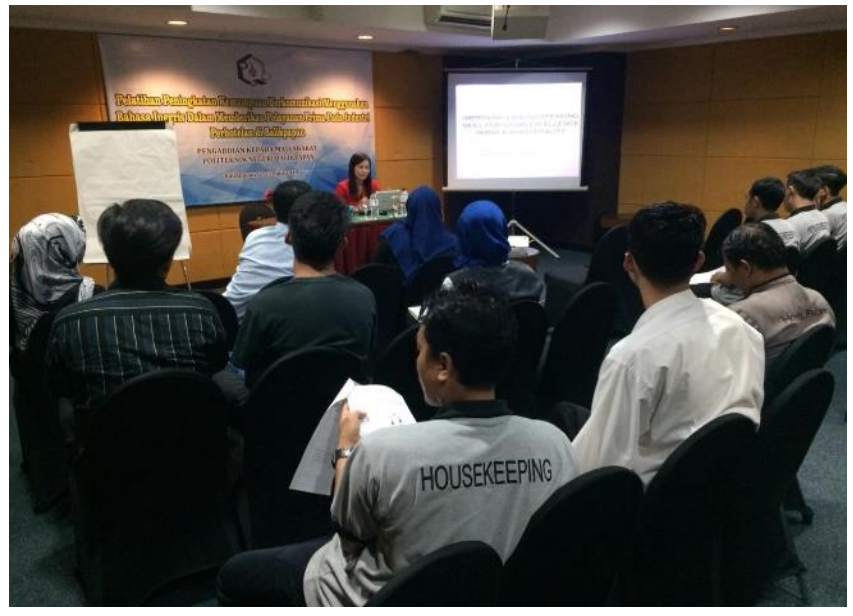

Gambar 2 Pemberian materi ESP for Hospitality

Dalam pelatihan hari yang ke-3, para peserta pelatihan diberikan materi inti tentang industri perhotelan yang meliputi : fasilitas dan pelayanan hotel, fasilitas kamar, penjelasan sederhana tentang objek wisata, menawarkan jasa cucian,memberikan pengarahan mengenai status kamar, dan juga cara menghadapi complain dari tamu hotel dengan mengedapankan pelayanan prima. Setelah program pelatihan selesai, kemudian dilanjutkan dengan dengan kegiatan pendampingan kepada seluruh peserta pelatihan selama 3 minggu.

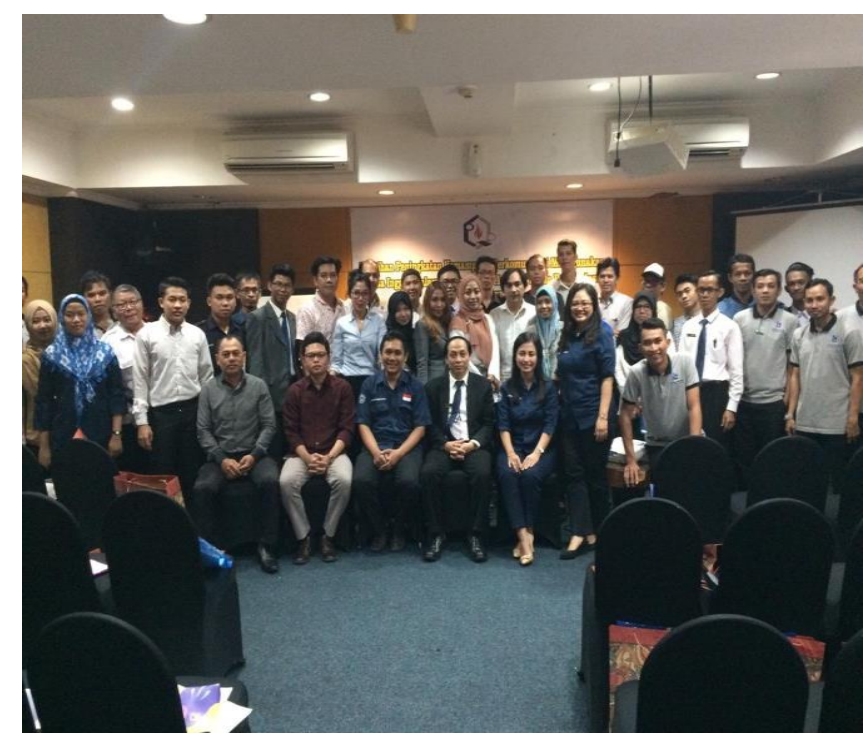

Gambar 3 Pendampingan Hasil Pelatihan dan Evaluasi Hasil Pelatihan

Dalam menyelengarakan pelatihan ini menggunakan beberapa metode, yakni: brainstorming, ceramah, tanya jawab, drilling, role play, intearctive talk, dan praktek. Untuk mengetahu sejauh mana target output sasaran dala pelatihan ini, maka setelah melakukan pendampingan,tim PKM melakukan evaluasi mengenai perkembangan kemampuan peserta pelatihan dalam berkomunikasi menggunakan bahasa 
dengan mengedepankan pelayanan prima. Tim PKM, telah mencoba memberikan post test terhadap setiap peserta pelatihan dengan menggunakan role play dimana Tim PKM menjadi berperan sebagai tamu hotel dan mereka bekerja sesuai posisi masing-masing sesuai dengan divisi kerjanya menggunakan bahasa Inggris secara keseluruhan. Berdasarkan hasil evaluasi dapat disimpulkan bahwa setelah melakukan pelatihan, setiap peserta memiliki peningkatan kemampan berkomunikasi menggunakan bahasa Inggris dan secara otomastis karena mengingat bahasa merupakan alat komunikasi terpenting dalam memberikan pelayanan prima kepada tamu khususnya tamu manca negara sehingga mereka tidak takut dan malu lagi jika harus menghadapi tamu mancanegara dengan berbekal materi pelatihan serta handbook yang telah diberikan kepada setiappeserta pelatihan dan dapat dijadikan sebagai pegangan mereka ketika mereka bekerja dan bertemu dengan tamu hotel mancanegara.

\section{Kesimpulan dan Saran}

Dalam kegiatan PKM ini yakni dengan memberikan pelatihan peningkatan kemampuan berkomunikasi menggunakan bahasa Inggris dalam memberikan pelayanan prima pada industri perhotelan dapat memberikan efek positif bagi industri perhotelan dalam peningkatan kemampuan staff hotel memberikan pelayanan prima khususnya kepada tamu mancanegara, dan berdasarkan hasil pendampingan dan evaluasi hasil pelatihan dinyatakan bahwa terjadi signifikan kemajuan kemampuan Bahasa Inggris staff perhotelan pada hotel Pasific dalam berkomunikasi dengan tamu mancanegara seiring dengan naiknya presentasi pengunjung mancanegara yang menggunakan bahasa Inggris sebagai Bahasa internasional. Selain itu, tim PKM juga memberikan handbook kepada setaip peserta pelatihan sebagai pegangan mereka ketika ingin mengingat kembali materi ESP for hospitality. Adapun saran dalam kegiatan PKM ini yakni perlu adanyanya pembinaan kemampuan bahasa Inggris staff perhotelan secara berkala guna dapat meningkatkan kapasitas kemampuan berkomunikasi menggunakan bahasa inggris mengingat target sasaran di industri yakni menawarkan jasa, sehingga kelancaran dalam berkomnikasi merupakan aspek terpenting guna terwujudnya pelayanan prima.

\section{Ucapan Terima Kasih}

Ucapan terima kasih kami sampaikan kepada pihak PoliteknikNegeri Balikpapan khususnya Pusat Penelitian dan Pengabdian Kepada Masyarakat (P3M) yang telah mendanai program kegiatan PKM ini, dan juga mitra PKM yakni hotel Pasific Balikpapan, serta seluruh tim PKM yang ikut terlibat dalam penyelenggraan pelatihan ini sehingga kegitan PKM ini dapat berlangsung dengan baik dan lancar.

\section{Daftar Rujukan}

Muliana, I Wayan. (2017). Moduel English 1 : Room Devision Management. Bali : Sekolah TinggiPariwisata Bali.

Rumekso. (2002). Houskeeping Hotel Floor Section. Yogyakarta : Andi.

Suryadharma, I \& Nurcahya, I. (2015). Pengaruh Kualitas Pelayanan pada Kepuasan Pelanggan Hotel Bintang Pesona di Denpasar Timur. E-Journal manajemen Unud , 4(4), 930-942

Susanti, Nila \& Rukiati, Enik (2017). Pelatihan Bahasa Inggris bagi Karang Taruna di Desa Wisata Lombok Kulon Bondowoso. Seminar Nasional Hasil Pengabdian kepada Masyarakat, (pp. 251-256). Jember.

Susepti, Amalia,dkk. (2017). Pengaruh Kualitas Pelayanan Terhadap Kepuasan dan Loyalitas Tamu Hotel. Jurnal Administrasi Bisnis, 50(5), 27-36. 